\title{
Guidelines
}

\section{Pediatric Airway Endoscopy: Recommendations of the Society for Pediatric Pneumology}

\author{
Dirk Schramm $^{a}$ Nadine Freitag ${ }^{a}$ Thomas Nicolai $^{b}$ Anna Wiemers ${ }^{c}$ \\ Bernd Hinrichs $^{d}$ Peter Amrhein ${ }^{\text {e }}$ Diana DiDio ${ }^{e}$ Christoph Eich $^{f}$ \\ Bernd Landsleitner $^{g}$ Ernst Eber ${ }^{h}$ Jürg Hammer ${ }^{i}$ on behalf of the Special \\ Interest Group on Pediatric Bronchoscopy of the Society for Pediatric \\ Pneumology (GPP) and invited Societies involved in pediatric airway endoscopy \\ ${ }^{a}$ Department of General Pediatrics, Neonatology, and Pediatric Cardiology, University Children's Hospital

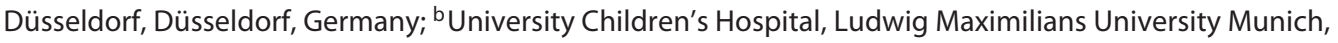 \\ Munich, Germany; ${ }^{C}$ Ruhr University Bochum, St. Josef-Hospital, University Hospital of Pediatrics and Adolescent

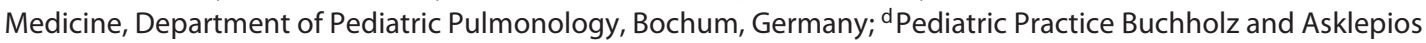

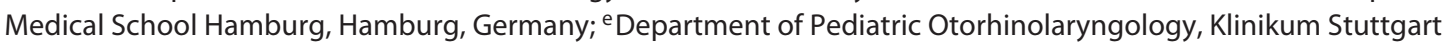 \\ Katharinenhospital, Olgahospital, Stuttgart, Germany; ${ }^{\mathrm{D}}$ Department of Anesthesia, Pediatric Intensive Care and \\ Emergency Medicine, Auf der Bult Children's Hospital, Hannover, Germany; ${ }^{9}$ Department of Anaesthesia and \\ Intensive Care Medicine, Hallerwiese Clinic-Cnopf Children's Hospital, Nuremberg, Germany; ${ }^{\text {h} D i v i s i o n ~ o f ~}$ \\ Paediatric Pulmonology and Allergology, Department of Paediatrics and Adolescent Medicine, Medical University \\ of Graz, Graz, Austria; 'Division of Respiratory and Critical Care Medicine, University Children's Hospital Basel, \\ University of Basel, Basel, Switzerland
}

\section{Keywords}

Pediatric bronchoscopy · Airway · Endoscopy ·

Pneumology · Guideline

Invited societies involved in pediatric airway endoscopy: Society for Neonatology and Pediatric Intensive Care Medicine (GNPI), German Society for Pediatric and Adolescent Medicine (DGKJ), Austrian Society of Pneumology (ÖGP), Working Group for Pediatric ENT Medicine of the German Society for Otolaryngology, Head and Neck Surgery (DGHNOKHC), and the Scientific Working Group for Pediatric Anesthesia (WAKKA) of the German Society of Anesthesiology and Intensive Care Medicine (DGAI).

\begin{abstract}
For many decades, pediatric bronchoscopy has been an integral part of the diagnosis and treatment of acute and chronic pulmonary diseases in children. Rapid technical advances have continuously influenced the performance of the procedure. Over the years, the application of pediatric bronchoscopy has considerably expanded to a broad range of indications. In this comprehensive and up-to-date guideline, the Special Interest Group of the Society for Pediatric Pneumology reviewed the most recent literature on pediatric bronchoscopy and reached a consensus on a safe technical performance of the procedure.
\end{abstract}

(c) 2021 S. Karger AG, Basel karger@karger.com

www.karger.com/res

Karger ${ }^{\prime \prime}=$
() 2021 S. Karger AG, Base

Correspondence to:

Dirk Schramm, dirk.schramm@med.uni-duesseldorf.de 


\title{
Content
}

\author{
1. Introduction \\ 1.1. Methodology \\ 1.2. Requirements \\ 1.2.1. Hygiene
}

\section{Indications}

2.1. Stridor

2.2. Diagnostic and Therapeutic Bronchoalveolar Lavage

2.3. Persistent Atelectasis

2.4. Tracheoesophageal Fistulas

2.5. Laryngeal Clefts

2.6. Suspected Endobronchial Lesions, Tumors

2.7. Pulmonary Hemorrhage

2.8. Obstructive Sleep Apnea Syndrome

2.9. Follow-Up after Lung Transplantation

2.10. Tracheostomy

2.11. Suspected Foreign Body Aspiration

2.12. Intensive Care and Anesthesia

\section{Preparation}

3.1. Documentation

3.2. Personnel

3.3. Qualification

3.4. Laboratory and Radiological Findings

3.5. Pre- and Post-Monitoring

3.6. Consent and Information

3.7. Anesthesia

3.7.1. Possible Drug Regimes for Anesthesia and (Analgo-)Sedation

\section{Performance}

4.1. Flexible Bronchoscopy

4.1.1. Transnasal Access

4.1.2. Access via Laryngeal Mask

4.1.3. Access via Tracheal Tube

4.1.4. Access via Tracheostomy Tube

4.1.5. Diagnostic Bronchoalveolar Lavage

4.2. Rigid Endoscopy

4.2.1. Rigid Laryngoscopy

4.2.2. Rigid Tracheobronchoscopy

\section{Interventional Procedures}

5.1. Extraction of Foreign Bodies

5.2. Brush Biopsy and Mucosal Biopsy

5.3. Transbronchial Biopsy

5.4. Other Interventional Procedures

\section{Risks and Complications}




\section{Introduction}

For many decades, bronchoscopy has been a crucial component of pediatric pulmonology. It offers valuable diagnostic and therapeutic possibilities far beyond the limits of pediatric pulmonology [1]. The aim of this guideline is to summarize the current knowledge and the various interdisciplinary aspects of pediatric bronchoscopy and to find a consensus on safe technical implementation. This should serve as a uniform basis for practical application.

\subsection{Methodology}

The Special Interest Group on Pediatric Bronchoscopy conducted a review of the literature published within the last 10 years through PubMed. The recommendations provided in this article are a result of our group's consensus process based on an extensive evaluation of the literature findings. The process of reaching consensus followed good scientific practice guidelines [2]. Recommendations that reached $>95 \%$ agreement among the authors were classified as strong consensus, whereas $>75 \%$ agreement was classified as consensus. The following societies were invited to participate in the guidelines: Society for Pediatric Pneumology (GPP), Society for Neonatology and Pediatric Intensive Care Medicine (GNPI), German Society for Pediatric and Adolescent Medicine (DGKJ), Austrian Society of Pneumology (ÖGP), Working Group for Pediatric ENT Medicine of the German Society for Otolaryngology, Head and Neck Surgery (DGHNOKHC) and the Scientific Working Group for Pediatric Anesthesia (WAKKA) of the German Society of Anesthesiology and Intensive Care Medicine (DGAI). The final text was thoroughly discussed among the members of the Special Interest Group on Pediatric Bronchoscopy, and a consensus was reached.

\subsection{Requirements}

\subsubsection{Hygiene}

With the technical progress in airway endoscopy, the reprocessing of the devices has become more demanding. The devices have sensitive optics and, because of their small size, are more difficult to clean. The goal of the cleaning process is to remove all organic materials and medicinal products without leaving any residue. When cleaning and disinfecting flexible endoscopes, a distinction is made between purely manual reprocessing, semimanual reprocessing with machine support, and machine reprocessing [3]. After cleaning, the endoscopes are dried properly and stored hanging in a closed endoscope cabi- net to ensure sterility and to prevent recontamination. If the endoscope is stored for longer than 14 days, sterility can no longer be guaranteed. All steps from transport to storage, including manual cleaning and/or mechanical preparation should be well coordinated and thoroughly documented. For quality assurance, the preparation success of the endoscopes and of the additional endoscopic instruments should be regularly checked (hygienic-microbiological checks).

Rigid endoscopes can be steam sterilized. The process recommendations for thermostable surgical instruments equally apply to endoscopes. Steam sterilization is carried out at $134^{\circ} \mathrm{C}$ with a minimum holding time of $5 \mathrm{~min}$, provided that pre-treatment (pre-cleaning, cleaning, disinfection) has been carried out. Rigid tubes and the additional instruments are then sterilely packed and stored individually or in trays. Stored instruments can safely be assumed sterile for a maximum of 6 months but not longer than the expiration date, which should be noted on the packaging. The storage should be dry, protected from dust and light, and separate from non-sterile medical devices.

Recommendation. Regardless of the procedure choice, the pre-cleaning of the endoscope should be done immediately after use, while it is still connected to the suction and the light source (strong consensus).

\section{Indications}

A bronchoscopy is indicated for children with refractory, chronic respiratory symptoms, recurrent or persistent pneumonia, and/or radiological abnormalities if non-invasive methods cannot elucidate the causes. A bronchoscopy allows among others to detect or exclude fixed and dynamic stenoses (malacias), endobronchial foreign bodies, mucus plugging, aberrant vessels, and airway compression by cardiac structures.

\subsection{Stridor}

One of the most common indications for pediatric airway endoscopy is congenital stridor or stridor manifesting in early infancy. The most common cause of congenital stridor is laryngomalacia, which can be diagnosed clinically in most patients by its typical symptoms [4]. If there is doubt about the diagnosis of laryngomalacia or if the course of the disease is severe, an endoscopic examination should be considered. Up to $10 \%$ of infants with stridor may have combined upper and lower respiratory tract pathologies. Flexible bronchoscopy provides the 
Table 1. Suspected diseases that indicate a diagnostic workup with bronchoalveolar lavage $[15,19-24]$

- Protracted bacterial bronchitis

- Recurrent and/or persistent bronchial obstruction in infants

- Pulmonary alveolar proteinosis

- Langerhans cell histiocytosis

- Lipoid pneumonia

- Alveolar microlithiasis

- Diffuse alveolar hemorrhage

- Tuberculosis

- Interstitial pneumonia

- Exogenous allergic alveolitis

- Pulmonary hemosiderosis

- Recurrent aspiration

- Sarcoidosis

best diagnostic results in assessing vocal cord movement and laryngeal or tracheal stability. Awake laryngoscopy can be considered as an alternative method to assess congenital stridor. Additionally, the sole laryngeal examination while the child is awake and breathing spontaneously can be considered.

In children with congenital stridor, there are several indications for timely endoscopic evaluation including but not limited to the following: worsening of stridor, cyanosis, apnea, choking while feeding, or persistence of stridor beyond the first year of life. In case of newly occurring stridor, its progression and persistence as well as therapy-refractory stridor post-extubation are considered indications for bronchoscopy. Endoscopy should exclude possible injuries and intubation obstructions due to laryngitis, cysts, or subglottic stenosis [5-10]. In addition to the possibility of using a flexible bronchoscope, this examination can also be performed by rigid laryngoscopy or microlaryngoscopy (MLS).

Recommendation. In an infant with an inspiratory stridor only, no apneic or cyanotic attacks, no progressive noisy breathing, and thriving well, clinical assessment is often sufficient for a suspected diagnosis of laryngomalacia. The progression over time, the child's thriving, and other symptoms should be observed regularly (strong consensus).

\subsection{Diagnostic and Therapeutic Bronchoalveolar \\ Lavage}

Bronchoalveolar lavage (BAL) is a crucial part of an extended pediatric pulmonological diagnostic workup because it is the only way to obtain objectifiable parameters on the type and the extent of a bronchoalveolar inflammation (e.g., bronchial asthma) and the pathogens (e.g., protracted bacterial bronchitis). In the setting of suspected interstitial and alveolar processes, cytopathological examination of the BAL can exclude pathologies such as pulmonary alveolar proteinosis or provide further diagnostic information [11-19] (Table 1).

In patients with cystic fibrosis (CF), BAL can be useful if sputum samples cannot be obtained and in cases where the source of a suspected infection is unclear. Routine BAL for evaluation of therapeutic success should be avoided in CF patients, and the benefits of BAL should be carefully weighed against the risk of anesthesia $[25,26]$.

In individual cases of pulmonary tuberculosis, BAL is necessary for pathogen isolation [27].

In immunodeficient patients with pulmonary infections, it is also possible to perform infectiological analysis of the BAL in addition to the pathogen identification in blood cultures and other (serological) samples [22, 28]. Unclear pulmonary infiltrates in patients prior to bone marrow transplantation can be diagnosed and treated with bronchoscopy, BAL, and/or brush biopsy [29].

BAL is therapeutically effective in children with certain forms of alveolar proteinosis. In these cases, the lung section should be lavaged in portions with large amounts of heated $0.9 \% \mathrm{NaCl}$ solution until only clear fluid can be aspirated. This procedure represents a particular anesthesiological and intensive care challenge due to the small airways and the respiratory insufficiency that is usually prevalent in children with certain forms of alveolar proteinosis. Since the suitable double-lumen tubes for singlelung ventilation for children under 8 years old are not available, the lavage, in this case, is performed using an endoscopically placed balloon catheter (bronchus blocker or, alternatively, pulmonary artery catheter) $[17,30-$ 32].

Recommendation. BAL is an important associated procedure of airway endoscopy in children and adolescents. It is used, among other things, for cytological assessment of the type and degree of inflammation, as well as for microbiological diagnostics (strong consensus).

\subsection{Persistent Atelectasis}

Pulmonary atelectasis is caused by increased mucus production, mucosal edema, and impaired mucociliary clearance. Flexible bronchoscopy should be used to find the exact cause and as a therapeutic measure. In the case of persistent atelectatic lung changes, despite sufficiently intensive curative measures, bronchoscopic reopening should be attempted with a flexible endoscope not later than 4-6 weeks after the diagnosis. If necessary, it should include targeted instillation of deoxyribonucle- 
ase (DNase), aspiration of the obstructing secretion, or insufflation of oxygen [33]. In order to be able to apply the endobronchial medications in a targeted manner, prior imaging is necessary. Whether a conventional $\mathrm{X}$ ray image is sufficient or a computed tomography scan of the chest is necessary should be decided on a case-bycase basis.

Another cause of persistent atelectasis is surfactant deficiency. In ventilated patients, a targeted application of surfactant (5-10 mg/mL, total dose 120-240 mg) can be carried out after all therapeutic measures (e.g., physiotherapy, positive end-expiratory pressure ventilation, antibiotics) have been exhausted [34]. Surfactant deficiency or defects occur more frequently in patients with $\mathrm{CF}$, acute respiratory distress syndrome, congenital diaphragmatic hernia, and patients undergoing Fontan surgery.

\subsection{Tracheoesophageal Fistulas}

Both flexible and rigid bronchoscopy are suitable for diagnosing suspected congenital or acquired tracheoesophageal fistulas. The endoscopic search for isolated tracheo- or bronchoesophageal fistulas can be difficult, as fistula openings can only be visible to a limited extent. For better visualization, assisted ventilation can be used to create positive pressure in the airways, although it is associated with the risk of gastric air insufflation and subsequent decrease of pulmonary compliance. Congenital tracheoesophageal fistulas in esophageal atresia may be marked preoperatively via rigid or flexible bronchoscopy. A wire, a catheter, or a ureteral stent can be used, thus making it easier for the surgeon to find the fistula duct intraoperatively [35].

Furthermore, acquired tracheoesophageal fistulas can be visualized in the trachea by application of dye (e.g., methylene blue or toluidine blue) or air applied via an esophageal probe. To increase the transfer of contrast agent and/or dye from the esophagus to the trachea, especially in the case of small fistulas, the administration can be performed under pressure between 2 inflated balloons positioned in the proximal and distal parts of the esophagus [36, 37].

\subsection{Laryngeal Clefts}

MLS is suitable for diagnosing laryngeal and/or laryngotracheal clefts in newborns/infants. However, the safe exclusion of a laryngeal cleft can only be achieved if the posterior commissure can be visualized with an instrument, for example, a laryngeal spreader. Laryngeal spreaders are also suitable for diagnosing other laryngeal pathologies. Furthermore, there is a possibility of flexible endoscopy with continuous positive airway pressure at $10-15 \mathrm{~cm} \mathrm{H}_{2} \mathrm{O}$ via an endoscopy mask (according to Frei et al. [38]) or by using a swivel adapter (also referred to as Mainz adapter) to visualize laryngeal fissures [39].

\subsection{Suspected Endobronchial Lesions, Tumors}

In clinically and radiologically suspected endobronchial lesions or tumors, flexible bronchoscopy is suitable as an early step for diagnostic evaluation. Patients with lymph node tuberculosis and signs of respiratory tract compression/infiltration may require a switch to a rigid endoscope. Tuberculous lymph node invasions with obstruction of bronchi can be reopened by suctioning and removal of the cheese-like lymphatic material [40,41]. In endobronchial lesions or tumorous tissue, a higher bleeding risk has to be accounted for; therefore, local hemostatic measures should be readily available.

\subsection{Pulmonary Hemorrhage}

In pulmonary hemorrhage, in addition to imaging techniques, both flexible and rigid endoscopy can be performed to locate the source of bleeding, determine the cause of bleeding, obtain secretion samples, and keep the airway free of blood. The choice of instrument also depends on the amount of blood. For larger bleedings, the rigid technique should be preferred.

Endoscopically, drugs for vasoconstriction (e.g., $1 \mathrm{mg}=$ $5 \mathrm{~mL}$ Glypressin ${ }^{\circledR}$ bolus through the endoscope plus approx. $5 \mathrm{~mL}$ air) or for inhibiting fibrinolysis (e.g., $500 \mathrm{mg}$ tranexamic acid in $20 \mathrm{~mL} \mathrm{NaCl} 0.9 \%$ ) can be applied as close as possible to the source of bleeding [42-44]. After the bleeding ceased, the area can be rinsed with saline solution $(5-10 \mathrm{~mL})$ to remove endobronchial blood and fibrin residues, and to ensure an optimal view of the lesion [42]. This procedure also applies to bleedings as a result of interventions such as biopsies, and so on. Furthermore, in cases of massive pulmonary hemorrhage, there is the possibility of lavage with cold saline solution, lung isolation by double lumen tube or bronchus blocker. In case of segmental bleeding, a balloon/Fogarty catheter can be used to compress the source of the bleeding. It is also important to position the patient correctly on the bleeding side (if known).

\subsection{Obstructive Sleep Apnea Syndrome}

Sleep endoscopy, also referred to as sleep nasoendoscopy or drug-induced sleep endoscopy, uses flexible endoscopes and allows to examine the upper airways under sedation. Sleep endoscopy does not replace poly(somno) 
graphs in the diagnostic pathway of obstructive sleep apnea syndrome (OSAS) but can add additional information before possible surgical and/or conservative measures and in assessing the success of an intervention. There is also a possibility of conducting an audio-video recording at the same time. It should be noted, however, that sedatives (including benzodiazepines) reduce laryngopharyngeal muscle tension, which can affect the outcome of sleep endoscopy [45-48]. Benzodiazepines can also prolong the post-interventional monitoring period; therefore, they should be used with caution as pre-medication in children with OSAS.

\subsection{Follow-Up after Lung Transplantation}

After lung transplantation, surveillance bronchoscopies are frequently performed using a flexible bronchoscope to endoscopically evaluate the transplant, and to perform transbronchial biopsies and/or BALs. Depending on age and compliance, flexible bronchoscopy is performed while the patient is awake.

\subsection{Tracheostomy}

After tracheostomy, flexible endoscopy should be used to check the position of the cannula and the occurrence of possible complications, such as pressure damage, using flexible endoscopy. Initially, it should be done at shorter intervals and then at least once a year [49].

\subsection{Suspected Foreign Body Aspiration}

A common indication for diagnostic and interventional bronchoscopy, especially in young children, is foreign body aspiration. Bronchoscopy should be performed in the case of a suspected medical history and/or clinical suspicion, even if the chest X-ray findings are normal or non-typical, because no other diagnostic procedure can exclude or verify foreign body aspiration [50]. For the primary assessment of the hypopharynx, larynx, and, if necessary, the esophagus entrance, an examination with a suitable video laryngoscope is recommended. Rigid bronchoscopy with a secured airway is an established technique for foreign body removal [51, 52]. A large case series published in 2012 showed a procedureassociated mortality rate of $0.2 \%$ ( 2 of 953 extractions [53]). A literature review of 12,979 cases found a mortality rate of $0.42 \%$ and severe complications in $0.96 \%$ of the procedures [54]. If a foreign body aspiration is anamnestically and clinically rather unlikely, but should be excluded due to the overall condition, then a potentially atraumatic, flexible bronchoscopy should be primarily performed. The possibility of switching to a rigid bron- choscope for extraction should be always available directly on site [32, 55-60].

When extracting foreign bodies using flexible bronchoscopy, the airway can be accessed via a laryngeal mask or a tracheal tube. The American Thoracic Society (ATS) recommends rigid bronchoscopy for foreign body extraction in children, at least for foreign bodies that could obstruct the airway [61].

Recommendation. If there is a history and/or clinical suspicion of foreign body aspiration, it should be verified or excluded by tracheobronchoscopy. A flexible bronchoscopy should primarily be performed for exclusion of foreign body aspiration. For the foreign body extraction, rigid equipment is particularly recommended, and it should always be available on site for immediate use (strong consensus).

\subsection{Intensive Care and Anesthesia}

In the field of pediatric anesthesia and neonatological and pediatric intensive care medicine, there are numerous indications for diagnostic flexible and, if necessary, rigid endoscopy of the upper and lower airways [62, 63]. These include: severe refractory post-extubation stridor, frustrating extubation attempts, (planned) intubation in an (expected) difficult airway, before planned extubation after long-term ventilation (subglottic stenosis?), control of tracheal tube positioning, visual control (e.g., of palatal plates), specimen extraction in respiratory infections, diagnostics of obstructive respiratory disorders or atelectasis, the search for a foreign body, the examination of the airways after chest trauma, inhalative noxae, or burns. In addition, a donor lung can be evaluated endoscopically, including pathogen diagnostics, prior to possible explantation.

\section{Preparation}

\subsection{Documentation}

A bronchoscopy should be documented using image recording devices/software. Video recording is preferable to document dynamic airway changes, thus enabling an optimal assessment of the follow-up examinations. Unclear findings or possible indications for surgery can be evaluated with the help of a consulting specialist, without the need for a new examination. In addition, the video documentation allows for post-processing of the recording, for example, slow motion. There are indications in which the simultaneous recording of the breathing sounds provides a diagnostic benefit. 


\subsection{Personnel}

The bronchoscopy team should consist of a bronchoscopist and a bronchoscopy assistant. If the bronchoscopy is performed under general anesthesia, anesthesia should be performed by an anesthetist and an assistant with expertise in child care of all ages. (Analgo-) sedation may be performed by another physician and assistant, if both have expertise in procedural (analgo-)sedation of children of all ages, including, in particular, the ability to manage respiratory and cardiovascular complications.

\subsection{Qualification}

The Guidelines Group agrees with the recommendation of the ATS, that before their first unsupervised endoscopy, the examiner should have already performed bronchoscopy in children of all ages under supervision. In addition to learning the technical skills, sufficient experience is required above all to interpret the endoscopic findings. To date, there is no good evidence on the development and assessment of the bronchoscopist's competence in pediatric endoscopy. A minimum experience of 50 supervised pediatric endoscopies has been suggested [61]. Depending on the indication, the bronchoscopist should also be able to switch from an examination with the flexible endoscope to the rigid technique in order to spare the patient secondary diagnostic interventions and minimize the risk of a respiratory incident. If they are not able to do this by themselves, they have the responsibility to have a colleague with expertise in rigid bronchoscopy available immediately.

Endoscopists who perform rigid bronchoscopy largely for the purpose of removing foreign bodies develop expertise in this technique in children under repeated expert supervision by a person qualified in this field.

It is absolutely necessary for the examiner and the second physician responsible for anesthesia or sedation (anesthetist with expertise in the care of children of all age groups or physician with expertise in procedural [analgo-]sedation of children of all age groups) to have the skills and experience in order to carry out any necessary rapid intubation or airway protection of the child in the event of unexpected difficulties. The bronchoscopy assistant and/or assisting nurse should have sufficient experience in assisting with acute complications. In the case of complex pathologies, especially in connection with severe symptoms, a multidisciplinary team is often required.

Recommendation. Examiners should be trained in technique, performance, and management of complications prior to their first unsupervised bronchoscopy (strong consensus).

\subsection{Laboratory and Radiological Findings}

In general, there is no need for prior blood sampling and/or imaging. Depending on the patient's underlying disease and planned intervention, this should always be decided individually. However, if radiological findings of the lungs were previously obtained, these should always be assessed before the airway endoscopy is performed, for example to determine the location of BAL.

\subsection{Pre- and Post-Monitoring}

Pre-interventionally, vital signs should be monitored in infants and children with pre-existing respiratory problems (dyspnea, desaturation, apnea) as inpatients. In this way, apneas, drops in oxygen saturation, and so on, can be detected immediately and treated quickly, as well as the setting for the examination and/or follow-up monitoring can be adjusted accordingly (intensive care unit, etc.). Depending on the underlying disease and/or indication, a pre-interventional cardiorespiratory poly(somno) graphy may be required to assess the extent and frequency of sleep- and thus presumably anesthesia-associated breathing disorders. The necessity of an inpatient admission on the day before the examination is also medically justified in children from difficult family backgrounds with a lack of compliance at home.

Endocarditis prophylaxis is not required during bronchoscopy and BAL. However, this does not apply to procedures that involve obtaining tissue samples or opening infectious processes. The Guidelines Group agrees that the AHA-defined target group, that is suffering from an active bacterial respiratory tract infection at the time of bronchoscopy/BAL, should receive antibiotic for endocarditis prophylaxis. This is given as a single dose $30-60$ min before the examination or up to $2 \mathrm{~h}$ afterwards [64].

If the procedure of the diagnostic bronchoscopy is uncomplicated, the child can be discharged on the day of the examination. Depending on the intervention, the findings of the examination, the patient's age as well as their symptoms/complaints, the post-interventional monitoring should be performed, if necessary, in the intensive care unit. This always remains an individual decision.

Recommendation. Pre-interventional inpatient monitoring may be considered for respiratory diagnostics, to assess individual risks of endoscopy and anesthesia (consensus).

Endocarditis prophylaxis is not required routinely for either bronchoscopy or BAL, as the link between a noninvasive airway procedure in children and infectious endocarditis has not yet been established (strong consensus).
Schramm et al. 


\subsection{Consent and Information}

It is the opinion of this Guidelines Group, that education about and consent to bronchoscopy is essential in the preparation stage. Since the overall procedural risks result from the intervention and anesthesia/sedation risks, it must be diligently explained to all the parties involved. The impact on the respiratory tract should be given special consideration in the educational discussion. The use of standardized information and consent forms is recommended.

Informed consent documentation should include:

- Fasting, risk of aspiration of stomach contents and saliva with the danger of lung failure and permanent lung damage, especially with incompliance with the necessary fasting period

- Reaction to applied medication (allergic reactions, cardiovascular reactions, nausea/vomiting, etc.)

- Laryngospasm/bronchospasm

- Possible respiratory depression including intubation and ventilation.

The anesthesiologic information should include:

- Fasting, risk of aspiration of stomach contents and saliva with the danger of lung failure and permanent lung damage, especially if the fasting period is not observed

- Laryngospasm/ bronchospasm

- Swallowing difficulties and hoarseness

- Damage to teeth, throat, jaw and larynx, vocal cords, and injuries to the trachea

- Shortness of breath and permanently impaired tongue sensation

- Life-threatening metabolic disorders (e.g., malignant hyperthermia)

- Unwanted alertness during anesthesia

- Risks of intravenous cannulas and injections

- Allergic reaction to applied medication Information on flexible and/ or rigid laryngoscopy, tracheo-, bronchoscopy should include:

- The indication for the examination and possible consequences

- Procedure and the duration of the examination

Possible complications of flexible bronchoscopy. Pain, difficulty swallowing or breathing, injury to the mucous membranes of the upper and lower airways with the possible mucous membrane swelling including obstruction, mucous membrane bleeding, infection and perforation (pneumothorax, mediastinitis), fever.

Possible complications of rigid bronchoscopy. Pain, difficulty swallowing or breathing, swelling and injury to the mucous membranes of the upper respiratory tract, lar- ynx, damage to the vocal cords with permanent voice disorders (hoarseness), injury to the trachea or lungs with consecutive obstruction, bleeding, infection, and perforation (pneumothorax, mediastinitis). In the course of a foreign body removal: blockage of the respiratory tract due to changes in the position of foreign body or due to blood, remaining of foreign body residual, possible need for a repeated endoscopy.

\subsection{Anesthesia}

Respiratory tract endoscopies in children should be carried out either under general anesthesia or, in the case of flexible bronchoscopy, under deep analgosedation if appropriate. Exceptions include a bronchoscopy via tracheostomy tube, which is usually performed without sedation, short flexible endoscopic airway inspection up to supraglottic in the awake state with topical anesthesia if necessary, and swallowing diagnostics. To identify expected difficult airways, specific attention should be paid to risk factors in the patient's history and clinical exam.

Anesthesia should be carried out by a professionally assisted anesthetist with expertise in the care of children of all ages. (Analgo-)sedation may be performed by another professionally assisted physician with experience in intensive care medicine and expertise in procedural (analgo-)sedation of children of all ages, including the ability to manage respiratory and cardiovascular complications in particular.

Transition from deep sedation (patient can no longer be fully awakened, protective reflexes are partially lost) to general anesthesia is gradual and can occur interindividually at different drug doses [65]. The objectives should be hypnosis/amnesia and analgesia appropriate to the intervention, effective attenuation of undesirable respiratory reflexes (essentially laryngospasm and bronchospasm), and safe oxygenation.

In flexible bronchoscopy, spontaneous breathing should be maintained as needed to ensure the dynamic assessment of the airway stability. However, respiratory complications during bronchoscopies are much more likely to occur under too little rather than under too much anesthesia or (analgo-)sedation.

For general anesthesia or (analgo-)sedation, the following aspects play a role among others: If the airways are to be examined during dynamic respiration (e.g., for stridor, or suspected laryngo- or tracheomalacia), a largely normal spontaneous breathing should be maintained. In rigid airway endoscopy, on the other hand, it is particularly important that the child does not cough, strain, or fight back (buck) in order to avoid bronchial 
injuries. Thus, deep anesthesia, preferably with additional muscle relaxation, is recommended in rigid bronchoscopy.

In any case, a second physician should perform the anesthesia or (analgo-)sedation and monitor the respiratory tract, respiration/ventilation, and circulation. This can be best ensured by a professionally assisted anesthetist with proven expertise in the care of children of all age groups. In the case of (analgo-)sedation, this can also be done by another physician and assistant with proven expertise in the procedural (analgo-)sedation of children of all age groups.

When using propofol and other hypnotics, the physician should be trained in the safe handling of ventilation and intubation as well as the treatment of all cardiopulmonary side effects and complications. The examiner himself is not able to adequately monitor the depth of anesthesia or sedation and the vital functions in addition to performing the bronchoscopy [66-70]. Continuous monitoring of $\mathrm{SpO}_{2}$, electrocardiogram (ECG), blood pressure, and the end-tidal $\mathrm{CO}_{2}$ (etCO $\mathrm{et}_{2}$, in the case of endoscopy under general anesthesia) as well as complete documentation of all vital parameters should be ensured. Furthermore, clinical monitoring of the patient during bronchoscopy is an indispensable part of the peri-interventional safety concept. It includes assessment of breathing by inspecting the undressed upper body, that is, observing the thoracic excursions, auscultation, and recording of the respiratory rate by means of ECG [71].

In children from about 6 months of age, anxiolyticsedative premedication may be useful, for example, with midazolam p.o. (or rectally) approx. 20-30 min before the start of the anesthesia.

In the fasted child, anesthesia can be administered either intravenously or with inhaled anesthetics. The medical urgency of the tracheobronchoscopy should be agreed upon between the teams involved. The anesthesia risks in children without prior fasting or insufficiently prepared children, and of a non-optimal team expertise due to the time of day or day of the week must be weighed against the possible risks of a delayed endoscopy [72].

\subsubsection{Possible Drug Regimes for Anesthesia and (Analgo-)Sedation}

- Propofol, a hypnotic with a favorable context-sensitive half-time and effective suppression of respiratory reflexes, has made a well-controlled total intravenous anesthesia (i.e., intravenously applied hypnotic plus opioid) clinically practicable and thus made anesthesia for bronchoscopy easier and overall safer $[73,74]$.
- Balanced anesthesia with sevoflurane (or other volatile anesthetics) plus opioid for tracheobronchoscopy is also suitable. Disadvantages are the environmental contamination during endoscopy, the associated, possibly unreliable gas application, and the depth of anesthesia.

- Ketamine/esketamine is suitable, especially in combination with propofol, for analgosedation with maintained spontaneous breathing, possibly in combination with topical anesthesia (see below). Note the increased secretion production and the enhancement of laryngeal protective reflexes [75].

- In principle, all opioids commonly used in anesthesia can be used, that is, fentanyl, alfentanil, sufentanil, and remifentanil. The ultra-short acting opioid remifentanil, which is usually applied via a syringe pump, offers the advantage of optimal controllability of an adequate depth of analgesia ("on/off effect") due to its particularly favorable context-sensitive half-time.

- In addition to a profound depth of anesthesia, additional muscle relaxation is recommended for rigid respiratory tract instrumentation application, especially for foreign body extraction, in order to reliably prevent potentially bronchial-traumatic coughing, pressing, or defending (bucking) when instruments are inserted. Mivacurium appears to be particularly suitable for this purpose as a short-acting, non-depolarizing muscle relaxant, especially since duration of action remains well controllable even when administered repeatedly $[66,67,76]$. The use of longer-acting relaxants is possible (e.g., atracurium, rocuronium), but there is a risk of postoperative overhang. For the medium-duration muscle relaxant rocuronium, there is a specific antagonist, sugammadex [77].

Recommendation. If rigid instruments are used in children, bronchoscopy should always be performed under general anesthesia with muscle relaxation. Flexible bronchoscopy can be alternatively performed under sufficiently deep (analgo-)sedation, if necessary in combination with topical anesthesia (strong consensus).

General anesthesia should be administered by a professionally assisted anesthetist with proven expertise in the care of children of all ages. (Analgo-)sedation may be provided by another professionally assisted physician with proven expertise in procedural (analgo-)sedation of children of all ages, but never by the bronchoscopic examiner himself (strong consensus).
Schramm et al. 


\section{Performance}

\subsection{Flexible Bronchoscopy}

\subsubsection{Transnasal Access}

Pre-treatment of the nasal entrance or the nasal passages with a local anesthetic and decongestant nasal drops is recommended. These medications should be carefully re-aspirated prior to the endoscopy if necessary. The bronchoscope should then be inserted carefully while the child is breathing spontaneously, at least when the function or dynamics of the airways (e.g., laryngo-/tracheobronchomalacia, vocal fold paresis) are to be examined. It is advisable to always perform endoscopy under visual control, also in the area of the upper airways. It may be necessary to retract the endoscope several times for reorientation or to flush the suction channel.

A probe for oxygen supply should be inserted into the other nostril. An endoscope with an external diameter of approx. $3.5 \mathrm{~mm}$ is usually used for patients between 4 and $6 \mathrm{~kg}$ of body weight, and one with an external diameter of approx. $5 \mathrm{~mm}$ from the age of 5-6 years. For very young patients, a thinner instrument (approx. $2 \mathrm{~mm}$ diameter without suction channel, approx. $2.8 \mathrm{~mm}$ with suction channel) is used.

The bronchoscope can also be inserted through a normal ventilation mask using an angle piece with a port (swivel adapter) or through the port of a special bronchoscopy mask according to Frei et al. [38, 78]. This can be used especially in children $<2$ years of age, to supply oxygen and, if necessary, anesthetic gas, as well as a positive end-expiratory pressure to stabilize the hypopharynx and maintain an appropriate tidal volume during spontaneous breathing [79].

Vocal cord mobility should be documented in spontaneous breathing while the thoracic excursions should be simultaneously observed (distinction between active and passive/paradox vocal cord abduction). This examination (transnasal, flexible pharyngolaryngoscopy) can generally also be performed in the awake child, especially if sedation does not allow a sufficiently reliable evaluation of vocal fold movement.

A local anesthetic can be applied under endoscopic view to the vocal cord area (cumulative lidocaine dose max. $5 \mathrm{mg} / \mathrm{kg}$ body weight, e.g. $0.5-1 \mathrm{~mL} 1 \%$ lidocaine dose and $10 \mathrm{~mL}$ air into a syringe, then spray as a single dose through the working channel). This reduces the need for analgesic doses (reducing the risk of apnea and airway obstruction) but, like any manipulation of the airway, can trigger laryngospasm. In addition, the patient should be kept fasted sufficiently long after the application of local
Table 2. Exemplary sizes of laryngeal masks, inner diameter (according to manufacturer's specifications), max. possible tube for intubation via laryngeal mask, and respective size of the bronchoscope

\begin{tabular}{lllll}
\hline $\begin{array}{l}\text { LMA } \\
\text { size }\end{array}$ & $\begin{array}{l}\text { Patient } \\
\text { weight, kg }\end{array}$ & $\begin{array}{l}\text { Max. cuff } \\
\text { volume, } \\
\mathrm{mL}\end{array}$ & $\begin{array}{l}\text { Max. suitable endo- } \\
\text { tracheal tube ID for } \\
\text { intubation through } \\
\text { the laryngeal mask }\end{array}$ & $\begin{array}{l}\text { Bronchoscope, } \\
\mathrm{mm}\end{array}$ \\
\hline 1 & $<5$ & 4 & 3.5 & 2.7 \\
1.5 & $5-10$ & 7 & 4.0 & 3.0 \\
2 & $10-20$ & 10 & 4.5 & 3.5 \\
2.5 & $20-30$ & 14 & 5.0 & 4.0 \\
3 & $30-50$ & 20 & 6.0 (cuffed) & 5.0 \\
4 & $50-70$ & 30 & 6.0 (cuffed) & 5.0 \\
5 & $>70$ & 40 & 7.0 (cuffed) & 7.3 \\
\hline
\end{tabular}

Table 3. Exemplary different sizes of laryngeal masks and clear inner diameter (according to B. Landsleitner, Cnopfsche Kinderklinik, Nuremberg), ID inner diameter

\begin{tabular}{llll}
\hline LMA size & $\begin{array}{l}\text { Ambu }^{\circledR} \\
\text { AuraGain } \\
\text { min. ID, mm }\end{array}$ & $\begin{array}{l}\text { Ambu }^{\circledR} \\
\text { Aura-i } \\
\text { min. ID, mm }\end{array}$ & $\begin{array}{l}\text { Ambu }^{\circledR} \\
\text { AuraOnce } \\
\text { min. ID, mm }\end{array}$ \\
\hline 1 & 6.6 & 6.3 & 5.2 \\
$11 / 2$ & 7.2 & 6.9 & 7.3 \\
2 & 9.0 & 8.7 & 8.6 \\
$21 / 2$ & 10.2 & 10.0 & 8.5 \\
3 & 11.0 & 11.0 & 85 \\
\hline
\end{tabular}

anesthetics to the laryngeal area, as swallowing difficulties and consecutive aspiration can occur [80-82]. A misinterpretation of laryngeal stability or aggravation of an existing laryngomalacia in infants by topical lidocaine is not to be expected [83]. With adequate anesthesia or analgosedation, local anesthetic can usually be omitted.

Stability of the trachea should be assessed during calm spontaneous breathing and documented by video recording [84]. Tracheal stability can be misjudged during forced breathing.

All lobar bronchi should be examined. Additional doses of lidocaine may be useful. (Caution: Do not exceed a total dose of $5 \mathrm{mg} / \mathrm{kg}$, due to possible hypotension or bradycardia, for example). Lidocaine also has an antimicrobial effect; this should be taken into account when endotracheal and/or bronchial pathogens are obtained $[85,86]$.

A systematic approach (e.g., first right, then left bronchial system) should be adopted to prevent the overlooking of unexpected pathologies and anatomical variants. In case of loss of orientation, a new orientation in the 
Table 4. Endotracheal tubes and their relation to tracheal size and bronchoscope size

\begin{tabular}{lllll}
\hline Age group & $\begin{array}{l}\text { Average tracheal } \\
\text { diameter, } \mathrm{mm}\end{array}$ & $\begin{array}{l}\text { Tube } \\
\text { (ID), mm }\end{array}$ & $\begin{array}{l}\text { Bronchoscope } \\
\text { (outer diameter), } \\
\text { mm }\end{array}$ & $\begin{array}{l}\text { Tube } \\
\text { obstruction, } \\
\%\end{array}$ \\
\hline Premature/newborn babies & $\sim 2.5$ to 3.5 & 2.0 to 3.0 & 2.2 & 54 \\
\hline 0-24 months & $5.3 \pm 1.0 / 6.4 \pm 1.2$ & 3.5 to 4.5 & 2.2 & 54 to 19 \\
& & & 2.8 & 64 to 31 \\
\hline 2-4 years & $7.4 \pm 0.8 / 8.1 \pm 0.7$ & 4.5 to 5.5 & 2.8 & 39 to 26 \\
& & & 3.8 & 71 to 52 \\
\hline 4-8 years & $8.0 \pm 0.6$ to $9.2 \pm 1.1$ & 5.5 to 6.5 & 2.8 & 3.8 \\
& $9.0+0.9$ to $9.3+0.8$ & & 4.9 & 19 to 8 \\
\hline 8-18 years & $10.5 \pm 0.5$ to $13.7 \pm 1.7$ & 6.5 to 8.0 & 2.8 & 34 to 23 \\
& $10.7+0.6$ to $14+1.2$ & & 3.8 & 57 to 30 \\
& & & 4.9 & 72 to 47 \\
\hline
\end{tabular}

bronchial tree should always be performed by retracting the instrument towards the main carina.

If respiratory problems occur, the bronchoscopy should be interrupted until a sufficiently stable situation is restored.

\subsubsection{Access via Laryngeal Mask}

Alternatively, flexible bronchoscopy can be performed using a previously inserted laryngeal mask (laryngeal mask airway, LMA) as a conduit with a swivel adapter. Angled laryngeal masks with a short breathing tube and a stomach drainage channel (2nd generation) can be advantageous in this case. Beforehand, it should be checked whether the endoscope can be easily inserted through the laryngeal mask (Tables 2,3).

Within the same size of laryngeal masks, their inner diameter can vary up to $2.5 \mathrm{~mm}$ depending on the brand and manufacturer. These deviations should be taken into consideration (see Table 2 below).

Adequate anesthesia is necessary for the insertion of the laryngeal mask but slightly less than for tracheal intubation.

A laryngeal mask does not represent a definitive securing of the airways. It does not prevent laryngospasm, does not offer complete aspiration protection, and generally does not allow high ventilation pressures $\left(>20 \mathrm{~cm} \mathrm{H}_{2} \mathrm{O}\right)$. Thus, LMAs should only be used in fasted patients.

During flexible bronchoscopy via laryngeal mask, it is not possible to assess laryngeal stability and function or the airways above.
The bronchoscope shaft (caution: not the optic system) can be lubricated with silicone spray, and the distal end with the optic system or the charge-coupled device (CCD) chip can be dipped in anti-fogging agent. When choosing a product, for example, silicone spray, the manufacturer's recommendations should always be followed.

\subsubsection{Access via Tracheal Tube}

In endotracheally intubated and mechanically ventilated patients, flexible bronchoscopy can be performed via tracheal tube and a swivel adapter. The bronchoscope shaft (cave: not the optics) can be lubricated, for example with silicone spray, and the distal end with the optics or CCD chip can be dipped in anti-fogging agent. (When selecting silicone spray and anti-fogging agent, the manufacturer's recommendations for the endoscope should always be observed.) A second physician should monitor ventilation (thoracic excursion, etCO $\mathrm{CO}_{2}, \mathrm{SpO}_{2}$ ), as the airway obstruction caused by the inserted bronchoscope can lead to decreased oxygenation and decarboxylation due to hypoventilation, with life-threatening cardiorespiratory complications as a possible consequence. Manual fixation of the tube during the examination can minimize the risk of accidental Extubation [62]. The endoscope should be at least $1 \mathrm{~mm}$ thinner than the inner diameter of the endotracheal tube to avoid tube dislocation and equipment damage. The need for immediate re-tubation in case of accidental extubation should be anticipated and both material and qualified personnel resources should be readily available (Table 4 ). 
In flexible bronchoscopy of newborns/infants, the small difference between the tube ID and the outer diameter of the bronchoscope can lead to subtotal tube obstruction, thus impairing ventilation and oxygenation.

\subsubsection{Access via Tracheostomy Tube}

Routine control of the tube position should be carried out by means of flexible bronchoscopy in the awake patient. The endoscope should be advanced to the end of the tube, and then decannulation should be performed over the bronchoscope in situ. The proximal trachea should be visible up to the stoma. If the airways above the stoma are to be assessed, procedural anesthesia or analgosedation is necessary. Alternatively, a backwards/upwards view can be attempted after decannulation. However, in most cases, the view will be obstructed by a suprastomal tracheostomy granuloma.

\subsubsection{Diagnostic Bronchoalveolar Lavage}

Depending on the age of the patient, the use of a flexible bronchoscope with an external diameter of approx. $3.0-5.0 \mathrm{~mm}$ and a suction channel $1.2-2 \mathrm{~mm}$ is recommended.

To achieve better recovery, it is recommended that the $\mathrm{BAL}$ is performed in the middle lobe or lingula, as there is less collateral ventilation. In focal processes, however, the affected segment should always be examined.

After obturation of the respective bronchial lumen through the bronchoscope, which is advanced as far as possible, lavage is performed. If there are problems because of too little reflux, the bronchoscope should be retracted by about $0.5 \mathrm{~cm}$. In most commercially available endoscopes, the working channel opens laterally to the endoscopist's field of sight. In case of decreasing reflux, careful rotation of the bronchoscope can occasionally help.

BAL is performed by rinsing the bronchial lumen with 3-4 individual portions/aliquots of body-warm $0.9 \%$ $\mathrm{NaCl}$ solution. The administered volume for each rinse should be about $1 \mathrm{~mL} / \mathrm{kg}$ body weight and should not exceed $50 \mathrm{~mL}$. It is important that the position of the bronchoscope is not changed during the lavaging process. Each individual volume of $\mathrm{NaCl}$ is immediately re-aspirated into a separate collection container using either an attached syringe or the device's own suction valve.

If BAL is performed for the sole purpose of pathogen diagnostics, a single rinse may be sufficient. The first aliquot is usually used for microbiology and other infection diagnostics. The aliquots 2,3 , and 4 are pooled for cytological examination if necessary. In order to maintain cell vitality in the diagnosis of infections and cyto- logical examination, the samples should be processed quickly $(<4 \mathrm{~h}$ !). The identification of T-lymphocyte subpopulations should be considered in individual cases.

Within the scope of the bacteriological examination, a germ quantification should be carried out. Usually, a concentration of $>10^{5} \mathrm{CFU} / \mathrm{mL}$ (colony forming unit per milliliter) is considered clinically significant. The samples can be analyzed using mycological and virological methods, molecular biology, and surfactant protein analysis according to indication [13].

\subsection{Rigid Endoscopy}

Instabilities in the cervical spine or atlanto-occipital transition are considered relative contraindications for rigid bronchoscopy. Children with trisomy 21 [87], Goldenhar syndrome, and storage diseases (e.g., mucopolysaccaridosis) are regularly affected [88]. Rigid bronchoscopy should be used very restrictively and with great caution in children with possible or proven atlanto-occipital instability.

\subsubsection{Rigid Laryngoscopy}

Under the guidance of direct laryngoscopy using a laryngoscope blade, the rigid endoscope should be inserted to visualize larynx and proximal trachea, if possible without contact. Laryngeal imaging is also possible with a video laryngoscope (wide angle view, image, or video documentation) or a supporting autoscopy (supporting device with fixed laryngoscope, syn. microlaryngoscopy, supporting laryngoscopy). This enables the endoscopist to use their free hand for interventions.

If visualization is carried out through a surgical microscope, ambidextrous intervention is possible (MLS). This also enables palpation of the respective structures, which is indispensable in some diagnoses, including laryngeal cleft or aryfixation. Surgical microscope visualization is the method of choice especially for diagnosis and evaluation of a laryngeal cleft, in which a vocal fold spreader must be used. In pathologies of the larynx and subglottis, such as suspected laryngitis or intubation-related laryngeal stenosis (including post-failed extubation), local diagnosis is achieved by retracting the tube and inspecting the vocal folds and subglottis with the rigid endoscope.

\subsubsection{Rigid Tracheobronchoscopy}

The rigid bronchoscope is inserted transorally into the trachea, after the insertion of a suitable mouthguard and with the aid of a laryngoscope with a straight or curved spatula. The laryngoscope is then removed, and a support cushion is placed under the patient's shoulders. The en- 
doscope should then be advanced into various bronchial sections by tilting and turning the head (under visual control with the aid of an optic system extended to the distal end of the endoscopy tube).

In addition to adequate depth of anesthesia and muscle relaxation, important safety measures to avoid tracheobronchial injuries include supporting and fixing the respiratory bronchoscope with the leading hand on the patient's upper jaw and a constant view of the distal end of the bronchoscope tube by using optic systems [89].

The side port of the bronchoscope tube allows mechanical or manual ventilation of the patient. A ventilation regimen with high respiratory frequencies and very small tidal volumes can usually be used to ventilate or oxygenate, even if the airway is partially obstructed by instrumentation; it also minimizes disturbing thoracic movements, which is helpful in foreign body extraction.

Oxygenation is also possible with the aid of jet ventilation techniques (e.g., Ventrain ${ }^{\circledR}$ system via ventilation catheter/tube changer) or with high-flow oxygen insufflation.

Video recording should be used to document the findings and the injury-free bronchoscopy. It is possible to combine a fiberscope with the rigid bronchoscope, by advancing the fiberscope through the bronchoscope tube with a very small lumen.

Recommendation. The rigid bronchoscope tube is always inserted and advanced under visual control. In case of accidental injuries, it may be useful to check the extent by flexible bronchoscopy (strong consensus).

\section{Interventional Procedures}

\subsection{Extraction of Foreign Bodies}

The recommended technique for removing foreign bodies is rigid bronchoscopy. For foreign body extraction, forceps and all other instruments inserted through the bronchoscope tube should be used under visual control. Soft and fragile foreign bodies, for example nuts, should be encased to avoid scattering. In this method, the foreign body is fixed using the endoscope tube by carefully screwing it in and then pulling it out en-bloc with the tube under visual control (preferably in the headdown position). However, a new intubation with the rigid bronchoscope might be required to document the complete removal or to remove further foreign body parts.

At the end of any bronchoscopic examination or intervention, a final inspection of all bronchial sections should be performed to document that no injuries occurred and that all foreign body remains have been removed.

When trying to retrieve smaller and usually distally located foreign bodies, use of a flexible bronchoscope or a combined technique, consisting of a thin, flexible bronchoscope, guided through a rigid bronchoscope tube, can be considered. To remove the foreign body, special catcher baskets or grasping forceps are inserted through the working channel of the flexible device. It should be noted that it may not be possible to suck out secretions during this procedure. This can considerably impair visibility. In addition, flexible removal poses a challenge for the anesthesiologist in the context of procedure-dependent complications due to partial blockage of ventilation (in the case of flexible endoscopy via a rigid bronchoscope) or loss of the foreign body during passage.

\subsection{Brush Biopsy and Mucosal Biopsy}

Bronchial mucosal biopsies are obtained mainly for cilia diagnostics. Although nasal mucosal biopsies are most commonly used for this purpose, in some patients chronic inflammation (sinusitis, etc.) does not permit adequate assessment of the structure and motility of the nasal cilia [90]. It is important not to take mucosal biopsies from the main carina, as this area contains hardly any cilia. Instead, the bronchial mucosal biopsies should be obtained in the left and/or right bronchial system. Tissue samples can be obtained using a brush technique, which will usually only produce a small amount of tissue. The amount of material might be further reduced if the brush is withdrawn through the instrument channel of the endoscope. More material can be obtained with a forceps biopsy using either the flexible or the rigid technique. With the rigid technique, the pieces of tissue are considerably larger and are particularly suitable for electron microscopy of ciliary histology. Mucosal biopsy can also contribute to the diagnosis of endobronchial inflammation, infections (e.g., tuberculosis), and superficial tumor pathologies [91].

\subsection{Transbronchial Biopsy}

In cases where a mucous membrane or brush biopsy does not provide sufficient information about the tissue process, transbronchial biopsy should be considered. Contraindications for transbronchial biopsy include relevant pulmonary hypertension and relevant coagulation disorders. However, the biopsy of bronchial structures or pathologies is almost always possible and may be helpful or irreplaceable in diagnosis confirmation (tumors [92], atypical mycobacteriosis [93], sarcoidosis [94, 95], granulomatosis with polyangiitis [96]).
Schramm et al. 
The yield of lung tissue in transbronchial biopsy in childhood is relatively small, particularly due to the maximum possible forceps size. Especially in bronchoscopes with a working channel of $<1.8 \mathrm{~mm}$, the forceps size is too small for an adequate biopsy size, except for those required for routine surveillance after heart/lung transplantation. In order to detect rejection at an early stage, peribronchial changes must be checked regularly in lungtransplanted patients. These can usually be adequately detected in smaller biopsies [97].

There is little experience, and no published evidence to date on the safety and value of a cryoprobe for endobronchial biopsy in children [32]. In view of the difficultto-control size of the freezing area and the risk of serious bleeding, the applicability of this method to small children currently is still unclear.

In the setting of unclear interstitial processes, videoassisted thoracoscopic lung biopsy is the preferable diagnostic procedure [19].

The question of ciliary dysfunction should generally be answered by nasal epithelial sampling ("brush" or forceps biopsy), but if the primary findings are unclear and ciliary dysfunction is still highly suspected, a more invasive and technically more difficult bronchial biopsy may be performed [98-100].

Ultrasound-guided transbronchial needle biopsy (EBUS-TBNA from bronchial, EUS-B-FNA from esophageal) is not yet widely used in children. However, initial study results are promising and show that this is a safe and effective method for obtaining material from mediastinal lymph nodes and other peribronchial structures [101, 102].

\subsection{Other Interventional Procedures}

In children, laser surgery should be performed with a rigid endoscope or by means of supporting laryngoscopy (also referred to as MLS, supporting autoscopy) [32, 103, 104]. Lasers and cold instruments can be used to resect or incise supraglottic and subglottic cysts [105], or shortstretched scar stenosis [106]. Scarred stenoses with fresh granulation tissue can be treated with intra-lesional steroid injections. In this procedure, $40-80 \mathrm{mg}$ methylprednisolone are injected into the granulation tissue in the form of a ring through a butterfly cannula (wings are cut off beforehand). The needle is held and guided by an endoscopic forceps. A previously slightly curved needle simplifies the injections into the tracheal wall. Injections should be immediately followed by tissue reduction by laser and expansion of the bronchial lumen by balloon dilatation $[107,108]$.

For acute restitution or also for definitive improvement of the airway, localized stenoses can be dilated bronchoscopically using angiological or balloon catheters specifically developed for the airway. Inflammatory subglottic stenoses can be treated locally, in addition to steroid injection (as described above), also with a steroidcontaining ointment (e.g., preparations containing betamethasone dipropionate and gentamicin sulphate) under daily short anesthesia. The medication is either applied to the newly inserted tracheal tube or inserted into the glottis with a swab. It should always be applied as a thin film in a small dosage as the drug contains paraffin that increases the risk of lipid pneumonia.

Stent implantation for malacia and tracheal or bronchial stenosis is performed via rigid bronchoscopy. However, a flexible technique can be used beforehand to visualize the exact localization and extent of the narrowed area. Stent implantation is usually the last resort in children who cannot be weaned off the ventilation without this strategy of airway stabilization or who would suffer life-threatening obstructive attacks or recurrent respiratory infections [32, 109, 110]. Airway stenting should always be done in specialized centers with sufficient expertise in airway endoscopy. Adequate follow-up care of these patients is also absolutely necessary. In the case of malacias or stenoses caused by vascular compression or complete tracheal/bronchial cartilage rings, surgical correction should be performed first [111]. The appropriate stent type and size is selected according to the indication. For example, silicone stents, which are easy to remove, are preferred for tracheomalacia or tracheal stenosis, and stainless-steel stents, for bronchomalacia or bronchial stenosis [111]. There is currently insufficient experience with the use of biodegradable stents in children [112].

Closure of fistulas with adhesives by bronchoscopy has so far only been proved successful in isolated cases of recurrent fistulas after initial surgical treatment, when it was performed by highly experienced specialists $[37,113]$.

Systemic therapy with cidofovir or bevacizumab should be considered for the treatment of recurrent laryngeal papillomatosis.

\section{Risks and Complications}

Complications during bronchoscopy include: excessive coughing, pressing and fighting back (bucking), mucosal bleeding and swelling, laryngospasm, bronchospasm, unanticipated or prolonged apnea with desaturation (hypoxemia) and consecutive bradycardia, and pneumothorax [114]. 
Fever is one of the most common complications after bronchoscopy and usually occurs 4-9 h after the procedure $[114,115]$. Antibiotics should not be administered generally, but rather based on the endoscopic findings, for example, in bacterial bronchitis.

Other post-interventional complications are additional oxygen demand, coughing, and pneumothorax.

The overall likelihood of a life-threatening complication is very low and depends, among other things, on the individual risk of the patient, the expertise and skill of the bronchoscopist and his team, and/or the performed procedure [114].

\section{Acknowledgement}

The current article is a translation of an already published paper [116]. The authors are responsible for the contents of the guideline. The AWMF was only granted the rights of use by the authors.

\section{Statement of Ethics}

The authors adhered to the Principles of Transparency and Best Practice in Scholarly Publishing.

\section{Conflicts of Interest Statement}

D.S., N.F., T.N., A.W., B.H., P.A., D.D., C.E., B.L., E.E., and J.H. report no conflict of interest regarding the manuscript.

\section{Funding Sources}

The manuscript was prepared without financial support or funding.

\section{Author Contributions}

D.S., N.F., T.N., A.W., B.H., P.A., D.D., C.E., B.L., E.E., and J.H. have provided substantial contributions to the conception or design of the work and/or or the acquisition, analysis, or interpretation of data for the work and contributed to drafting the work and/ or revising it critically for important intellectual content and have given final approval of the version to be published and agree to be accountable for all aspects of the work in ensuring that questions related to the accuracy or integrity of any part of the work are appropriately investigated and resolved.

\section{References}

1 Wood RE. Spelunking in the pediatric airways: explorations with the flexible fiberoptic bronchoscope. Pediatr Clin North Am. 1984 Aug;31(4):785-99.

2 Robin Graham MM. Dianne Miller Wolman, Sheldon Greenfield, Earl Steinberg, editors. Clinical Practice Guidelines We Can Trust. In: Graham R, Mancher M, Miller Wolman D, Greenfield S, Steinberg E, editors. Clinical Practice Guidelines We Can Trust. Washington DC: 2011 by the National Academy of Sciences; 2011.

3 Pynnonen MA, Whelan J. Reprocessing Flexible Endoscopes in the Otolaryngology Clinic. Otolaryngol Clin North Am. 2019 Jun;52(3): 391-402.

4 Bluher AE, Darrow DH. Stridor in the Newborn. Pediatr Clin North Am. 2019 Apr;66(2): 475-88.

5 Barbato A, Magarotto M, Crivellaro M, Novello A Jr, Cracco A, de Blic J, et al. Use of the paediatric bronchoscope, flexible and rigid, in 51 European centres. Eur Respir J. 1997 Aug; 10(8):1761-6.

6 Balfour-Lynn IM, Spencer H. Bronchoscopy-how and when? Paediatr Respir Rev. 2002 Sep;3(3):255-64.

7 Nicolai T. Therapeutic concepts in upper airway obstruction. Paediatr Respir Rev. 2004 Mar;5(1):34-9.
8 Rutter MJ, Cohen AP, de Alarcon A. Endoscopic airway management in children. Curr Opin Otolaryngol Head Neck Surg. 2008 Dec;16(6):525-9.

9 Wood RE. Evaluation of the upper airway in children. Curr Opin Pediatr. 2008 Jun;20(3): 266-71.

10 Yonker LM, Fracchia MS. Flexible bronchoscopy. Adv Otorhinolaryngol. 2012;73:12-8.

11 Riedler J, Grigg J, Robertson CF. Role of bronchoalveolar lavage in children with lung disease. Eur Respir J. 1995 Oct;8(10):1725-30.

12 Connett GJ. Bronchoalveolar lavage. Paediatr Respir Rev. 2000 Mar;1(1):52-6.

13 de Blic J, Midulla F, Barbato A, Clement A, Dab I, Eber E, et al.; European Respiratory Society. Bronchoalveolar lavage in children. ERS Task Force on bronchoalveolar lavage in children. Eur Respir J. 2000 Jan;15(1):217-31.

14 Ratjen F, Nicolai T. Paediatric bronchoscopy. Paediatr Respir Rev. 2004;5 Suppl A:S21-2.

15 Deterding R. Evaluating infants and children with interstitial lung disease. Semin Respir Crit Care Med. 2007 Jun;28(3):333-41.

16 Shell R, Nicol K. Pediatric bronchoalveolar lavage: practical considerations and future prospects. Pediatr Dev Pathol. 2010 JulAug;13(4):255-64.
17 Griese M, Ripper J, Sibbersen A, Lohse P, Lohse P, Brasch F, et al. Long-term follow-up and treatment of congenital alveolar proteinosis. BMC Pediatr. 2011 Aug;11(1):72.

18 Meyer KC, Raghu G. Bronchoalveolar lavage for the evaluation of interstitial lung disease: is it clinically useful? Eur Respir J. 2011 Oct;38(4):761-9.

19 Kurland G, Deterding RR, Hagood JS, Young LR, Brody AS, Castile RG, et al.; American Thoracic Society Committee on Childhood Interstitial Lung Disease (chILD) and the chILD Research Network. An official American Thoracic Society clinical practice guideline: classification, evaluation, and management of childhood interstitial lung disease in infancy. Am J Respir Crit Care Med. 2013 Aug;188(3):376-94.

20 Green CG, Eisenberg J, Leong A, Nathanson I, Schnapf BM, Wood RE. Flexible endoscopy of the pediatric airway. Am Rev Respir Dis. 1992 Jan;145(1):233-5.

21 Schellhase DE, Fawcett DD, Schutze GE, Lensing SY, Tryka AF. Clinical utility of flexible bronchoscopy and bronchoalveolar lavage in young children with recurrent wheezing. J Pediatr. 1998 Feb;132(2):312-8.

22 Brennan S, Gangell C, Wainwright C, Sly PD. Disease surveillance using bronchoalveolar lavage. Paediatr Respir Rev. 2008 Sep;9(3):151-9. 
23 Narang R, Bakewell K, Peach J, Clayton S, Samuels M, Alexander J, et al. Bacterial distribution in the lungs of children with protracted bacterial bronchitis. PLoS One. 2014 Sep;9(9):e108523.

24 Dave MH, Gerber A, Bailey M, Gysin C, Hoeve H, Hammer J, et al. Prevalence and characteristics of tracheal cobblestoning in children. Pediatr Pulmonol.2015 Oct;50(10):9959.

25 Wainwright CE, Vidmar S, Armstrong DS, Byrnes CA, Carlin JB, Cheney J, et al.; ACFBAL Study Investigators. Effect of bronchoalveolar lavage-directed therapy on Pseudomonas aeruginosa infection and structural lung injury in children with cystic fibrosis: a randomized trial. JAMA. 2011 Jul;306(2):163-71.

26 Jain K, Wainwright C, Smyth AR. Bronchoscopy-guided antimicrobial therapy for cystic fibrosis. Cochrane Database Syst Rev. 2013 Dec;(12):CD009530.

27 Cakir E, Kut A, Ozkaya E, Gedik AH, Midyat L, Nursoy M. Bronchoscopic evaluation in childhood pulmonary tuberculosis: risk factors of airway involvement and contribution to the bacteriologic diagnosis. Pediatr Infect Dis J. 2013 Aug;32(8):921-3.

28 Bochennek K, Abolmaali N, Wittekindt B, Schwabe D, Klingebiel T, Lehrnbecher T. Diagnostic approaches for immunocompromised paediatric patients with pulmonary infiltrates. Clin Microbiol Infect. 2006 Mar; 12(3):199-201.

29 Chellapandian D, Lehrnbecher T, Phillips B, Fisher BT, Zaoutis TE, Steinbach WJ, et al. Bronchoalveolar lavage and lung biopsy in patients with cancer and hematopoietic stemcell transplantation recipients: a systematic review and meta-analysis. J Clin Oncol. 2015 Feb;33(5):501-9.

30 Reiter K, Schoen C, Griese M, Nicolai T. Whole-lung lavage in infants and children with pulmonary alveolar proteinosis. Paediatr Anaesth. 2010 Dec;20(12):1118-23.

31 Wilson CA, Wilmshurst SL, Black AE. Anesthetic techniques to facilitate lung lavage for pulmonary alveolar proteinosis in childrennew airway techniques and a review of the literature.PaediatrAnaesth.2015Jun;25(6):54653.

32 Eber E, Antón-Pacheco JL, de Blic J, Doull I, Faro A, Nenna R, et al. ERS statement: interventional bronchoscopy in children. Eur Respir J. 2017 Dec;50(6):1700901.

33 Slattery DM, Waltz DA, Denham B, O’Mahony M, Greally P. Bronchoscopically administered recombinant human DNase for lobar atelectasis in cystic fibrosis. Pediatr Pulmonol. 2001 May;31(5):383-8.

34 Krause MF, von Bismarck P, Oppermann HC, Ankermann T. Bronchoscopic surfactant administration in pediatric patients with persistent lobar atelectasis. Respiration. 2008;75(1): $100-4$.
35 Amat F, Heraud MC, Scheye T, Canavese M, Labbé A. Flexible bronchoscopic cannulation of an isolated H-type tracheoesophageal fistula in a newborn. J Pediatr Surg. 2012 Oct; 47(10):e9-10.

36 Kiyan G, Dağli TE, Tuğtepe H, Kodalli N. Double balloon esophageal catheter for diagnosis of tracheo-esophageal fistula. Eur Radiol. 2003 Feb;13(2):397-9.

37 Meier JD, Sulman CG, Almond PS, Holinger LD. Endoscopic management of recurrent congenital tracheoesophageal fistula: a review of techniques and results. Int J Pediatr Otorhinolaryngol. 2007 May;71(5):691-7.

38 Frei FJ, aWengen DF, Rutishauser M, Ummenhofer $\mathrm{W}$. The airway endoscopy mask: useful device for fibreoptic evaluation and intubation of the paediatric airway. Paediatr Anaesth. 1995;5(5):319-24.

39 Trachsel D, Hammer J. CPAP to diagnose laryngeal clefts by flexible endoscopy in infants. Pediatr Pulmonol. 2018 Sep;53(9):1284-7.

40 Goussard P, Gie R. Airway involvement in pulmonary tuberculosis. S Afr Med J. 2007 Oct;97(10 Pt 2):986-8.

41 Goussard P, Gie R. The role of bronchoscopy in the diagnosis and management of pediatric pulmonary tuberculosis. Expert Rev Respir Med. 2014 Feb;8(1):101-9.

42 Breuer HW, Charchut S, Worth H, Trampisch HJ, Glänzer K. Endobronchial versus intravenous application of the vasopressin derivative glypressin during diagnostic bronchoscopy. Eur Respir J. 1989 Mar;2(3):225-8.

43 Márquez-Martín E, Vergara DG, MartínJuan J, Flacón AR, Lopez-Campos JL, Rodríguez-Panadero F. Endobronchial administration of tranexamic Acid for controlling pulmonary bleeding: a pilot study. J Bronchology Interv Pulmonol. 2010 Apr;17(2):122-5.

44 Fekri MS, Hashemi-Bajgani SM, Shafahi A, Zarshenas R. Comparing Adrenaline with Tranexamic Acid to Control Acute Endobronchial Bleeding: A Randomized Controlled Trial. Iran J Med Sci. 2017 Mar;42(2): 129-35.

45 Ehsan Z, Mahmoud M, Shott SR, Amin RS, Ishman SL. The effects of anesthesia and opioids on the upper airway: A systematic review. Laryngoscope. 2016 Jan;126(1):270-84.

46 Blumen M, Bequignon E, Chabolle F. Druginduced sleep endoscopy: A new gold standard for evaluating OSAS? Part II: Results. Eur Ann Otorhinolaryngol Head Neck Dis. 2017 Apr;134(2):109-15.

47 Esteller E, Villatoro JC, Agüero A, Matiñó E, Lopez R, Aristimuño A, et al. Outcome of drug-induced sleep endoscopy-directed surgery for persistent obstructive sleep apnea after adenotonsillar surgery. Int J Pediatr Otorhinolaryngol. 2019 May;120:118-22.

48 Miller C, Kirkham E, Ma CC, Filipek N, Horn DL, Johnson K, et al. Polysomnography outcomes in children with small tonsils undergoing drug-induced sleep endoscopy-directed surgery. Laryngoscope. 2019 Dec;129(12): 2771-4.
49 Griese M, Felber J, Reiter K, Strong P, Reid K, Belohradsky BH, et al. Airway inflammation in children with tracheostomy. Pediatr Pulmonol. 2004 Apr;37(4):356-61.

50 Merkenschlager A, Sanktjohanser L, Hundt C, Schneider K, Nicolai T. [Diagnostic value of a plain radiograph of the chest in suspected tracheobronchial foreign body aspiration in children]. Pneumologie. 2009 Jun;63(6):325-8.

51 Nicolai T. The role of rigid and flexible bronchoscopy in children. Paediatr Respir Rev. 2011 Sep;12(3):190-5.

52 Boufersaoui A, Smati L, Benhalla KN, Boukari R, Smail S, Anik K, et al. Foreign body aspiration in children: experience from $2624 \mathrm{pa}-$ tients. Int J Pediatr Otorhinolaryngol. 2013 Oct:77(10):1683-8

53 Gang W, Zhengxia P, Hongbo L, Yonggang L, Jiangtao D, Shengde W, et al. Diagnosis and treatment of tracheobronchial foreign bodies in 1024 children. J Pediatr Surg. 2012 Nov; 47(11):2004-10.

54 Fidkowski CW, Zheng H, Firth PG. The anesthetic considerations of tracheobronchial foreign bodies in children: a literature review of 12,979 cases. Anesth Analg. 2010 Oct;111(4) 1016-25.

55 Martinot A, Closset M, Marquette CH, Hue V, Deschildre A, Ramon P, et al. Indications for flexible versus rigid bronchoscopy in children with suspected foreign-body aspiration. Am J Respir Crit Care Med. 1997 May;155(5): $1676-9$.

56 Swanson KL, Prakash UB, Midthun DE, Edell ES, Utz JP, McDougall JC, et al. Flexible bronchoscopic management of airway foreign bodies in children. Chest. 2002 May;121(5): 1695-700.

57 Midulla F, de Blic J, Barbato A, Bush A, Eber E, Kotecha S, et al.; ERS Task Force. Flexible endoscopy of paediatric airways. Eur Respir J. 2003 Oct;22(4):698-708.

58 Tang LF, Xu YC, Wang YS, Wang CF, Zhu $\mathrm{GH}, \mathrm{Bao} \mathrm{XE}$, et al. Airway foreign body removal by flexible bronchoscopy: experience with 1027 children during 2000-2008. World J Pediatr. 2009 Aug;5(3):191-5.

59 Goyal R, Nayar S, Gogia P, Garg M. Extraction of tracheobronchial foreign bodies in children and adults with rigid and flexible bronchoscopy. J Bronchology Interv Pulmonol. 2012 Jan;19(1):35-43.

60 Schramm D, Yu Y, Wiemers A, Vossen C, Snijders D, Krivec U, et al. Pediatric flexible and rigid bronchoscopy in European centersAvailability and current practice. Pediatr Pulmonol. 2017 Nov;52(11):1502-8.

61 Faro A, Wood RE, Schechter MS, Leong AB, Wittkugel E, Abode K, et al.; American Thoracic Society Ad Hoc Committee on Flexible Airway Endoscopy in Children. Official American Thoracic Society technical standards: flexible airway endoscopy in children. Am J Respir Crit Care Med. 2015 May;191(9): 1066-80. 
62 Bush A. Bronchoscopy in paediatric intensive care. Paediatr Respir Rev. 2003 Mar;4(1):6773.

63 Field-Ridley A, Sethi V, Murthi S, Nandalike K, Li ST. Utility of flexible fiberoptic bronchoscopy for critically ill pediatric patients: A systematic review. World J Crit Care Med. 2015 Feb;4(1):77-88.

64 Wilson W, Taubert KA, Gewitz M, Lockhart PB, Baddour LM, Levison M, et al. Prevention of infective endocarditis: guidelines from the American Heart Association: a guideline from the American Heart Association Rheumatic Fever, Endocarditis and Kawasaki Disease Committee, Council on Cardiovascular Disease in the Young, and the Council on Clinical Cardiology, Council on Cardiovascular Surgery and Anesthesia, and the Quality of Care and Outcomes Research Interdisciplinary Working Group. J Am Dent Assoc. 2007 Jun;138(6):739-45, 747-60.

65 Practice guidelines for sedation and analgesia by non-anesthesiologists. A report by the American Society of Anesthesiologists Task Force on Sedation and Analgesia by Non-Anesthesiologists. Anesthesiology. 1996 Feb; 84(2):459-71.

66 Jaggar SI, Haxby E. Sedation, anaesthesia and monitoring for bronchoscopy. Paediatr Respir Rev. 2002 Dec;3(4):321-7.

67 Machotta A. [Anaesthetic management for endoscopy of the pediatric airway]. Anaesthesist. 2002 Aug;51(8):668-78.

68 Dilos BM. Anesthesia for pediatric airway endoscopy and upper gastrointestinal endoscopy. Int Anesthesiol Clin. 2009;47(3):55-62.

69 Zhang J, Wang Y, Li B, Zhang W. Remifentail infusion for paediatric bronchoscopic foreign body removal: comparison of sevoflurane with propofol for anaesthesia supplementation for bronchoscope insertion. Anaesth Intensive Care. 2010 Sep;38(5):905-10.

70 Costi D, Cyna AM, Ahmed S, Stephens K, Strickland P, Ellwood J, et al. Effects of sevoflurane versus other general anaesthesia on emergence agitation in children. Cochrane Libr. 2014 Sep;(9):CD007084.

71 Nicolai T. Pediatric bronchoscopy. Pediatr Pulmonol. 2001 Feb;31(2):150-64.

72 Mani N, Soma M, Massey S, Albert D, Bailey CM. Removal of inhaled foreign bodiesmiddle of the night or the next morning? Int I Pediatr Otorhinolaryngol. 2009 Aug;73(8): 1085-9.

73 Hasan RA, Reddy R. Sedation with propofol for flexible bronchoscopy in children. Pediatr Pulmonol. 2009 Apr;44(4):373-8.

74 Lerman J, Jöhr M. Inhalational anesthesia vs total intravenous anesthesia (TIVA) for pediatric anesthesia. Paediatr Anaesth. 2009 May; 19(5):521-34.

75 Oberer C, von Ungern-Sternberg BS, Frei FJ, Erb TO. Respiratory reflex responses of the larynx differ between sevoflurane and propofol in pediatric patients. Anesthesiology. 2005 Dec;103(6):1142-8.
76 Liao R, Li JY, Liu GY. Comparison of sevoflurane volatile induction/maintenance anaesthesia and propofol-remifentanil total intravenous anaesthesia for rigid bronchoscopy under spontaneous breathing for tracheal/ bronchial foreign body removal in children. Eur J Anaesthesiol. 2010 Nov;27(11):930-4.

77 Chambers D, Paulden M, Paton F, Heirs M, Duffy S, Hunter JM, et al. Sugammadex for reversal of neuromuscular block after rapid sequence intubation: a systematic review and economic assessment. Br J Anaesth. 2010 Nov;105(5):568-75.

78 Niggemann B, Haack M, Machotta A. How to enter the pediatric airway for bronchoscopy. Pediatr Int. 2004 Apr;46(2):117-21.

79 Trachsel D, Erb TO, Frei FJ, Hammer J; Swiss Paediatric Respiratory Research Group. Use of continuous positive airway pressure during flexible bronchoscopy in young children. Eur Respir J. 2005 Nov;26(5):773-7.

80 Ertekin C, Kiylioglu N, Tarlaci S, Keskin A, Aydogdu I. Effect of mucosal anaesthesia on oropharyngeal swallowing. Neurogastroenterol Motil. 2000 Dec;12(6):567-72.

81 Lester S, Langmore SE, Lintzenich CR, Wright SC, Grace-Martin K, Fife T, et al. The effects of topical anesthetic on swallowing during nasoendoscopy. Laryngoscope. 2013 Jul;123(7): 1704-8.

82 Fife TA, Butler SG, Langmore SE, Lester S, Wright SC Jr, Kemp S, et al. Use of topical nasal anesthesia during flexible endoscopic evaluation of swallowing in dysphagic patients. Ann Otol Rhinol Laryngol. 2015 Mar;124(3): 206-11.

83 von Ungern-Sternberg BS, Trachsel D, Zhang G, Erb TO, Hammer J. Topical Lidocaine Does Not Exaggerate Laryngomalacia in Infants During Flexible Bronchoscopy Under Propofol Anesthesia. J Bronchology Interv Pulmonol. 2016 Jul;23(3):215-9.

84 Carden KA, Boiselle PM, Waltz DA, Ernst A. Tracheomalacia and tracheobronchomalacia in children and adults: an in-depth review. Chest. 2005 Mar;127(3):984-1005

85 Olsen KM, Peddicord TE, Campbell GD, Rupp ME. Antimicrobial effects of lidocaine in bronchoalveolar lavage fluid. J Antimicrob Chemother. 2000 Feb;45(2):217-9.

86 Chandan SS, Faoagali J, Wainwright CE. Sensitivity of respiratory bacteria to lignocaine. Pathology. 2005 Aug;37(4):305-7.

87 Ali FE, Al-Bustan MA, Al-Busairi WA, AlMulla FA, Esbaita EY. Cervical spine abnormalities associated with Down syndrome. Int Orthop. 2006 Aug;30(4):284-9.

88 McKay SD, Al-Omari A, Tomlinson LA, Dormans JP. Review of cervical spine anomalies in genetic syndromes. Spine. 2012 Mar;37(5): E269-77.

89 Helmers RA, Sanderson DR. Rigid bronchoscopy. The forgotten art. Clin Chest Med. 1995 Sep;16(3):393-9.
90 Gil HI, Lee T, Jeong BH, Lee H, Choe J, Ahn $\mathrm{K}$, et al. Additional role of bronchial mucosal biopsy for ciliary structural abnormality in diagnosis of primary ciliary dyskinesia. J Thorac Dis. 2019 Mar;11(3):839-47.

91 Bush A, Pohunek P. Brush biopsy and mucosal biopsy. Am J Respir Crit Care Med. 2000 Aug;162(2 Pt 2 supplement_1):S18-22.

92 Eyssartier E, Ang P, Bonnemaison E, Gibertini I, Diot P, Carpentier E, et al. Characteristics of endobronchial primitive tumors in children. Pediatr Pulmonol. 2014 Jun;49(6): E121-5.

93 Kröner C, Griese M, Kappler M, Schoen C, Hoffmann F, Nicolai T, et al. Endobronchial lesions caused by nontuberculous mycobacteria in apparently healthy pediatric patients. Pediatr Infect Dis J. 2015 May;34(5): 532-5.

94 Tessier V, Chadelat K, Baculard A, Housset B, Clement A. BAL in children: a controlled study of differential cytology and cytokine expression profiles by alveolar cells in pediatric sarcoidosis. Chest. 1996 Jun;109(6): $1430-8$.

95 Jindal SK, Gupta D, Aggarwal AN. Sarcoidosis in developing countries. Curr Opin Pulm Med. 2000 Sep;6(5):448-54.

96 Leslie KO, Gruden JF, Parish JM, Scholand MB. Transbronchial biopsy interpretation in the patient with diffuse parenchymal lung disease. Arch Pathol Lab Med. 2007 Mar; 131(3):407-23.

97 Hayes D Jr, Baker PB, Kopp BT, Kirkby S, Galantowicz M, McConnell PI, et al. Surveillance transbronchial biopsies in infant lung and heart-lung transplant recipients. Pediatr Transplant. 2013 Nov;17(7):670-5.

98 Barbato A, Frischer T, Kuehni CE, Snijders D, Azevedo I, Baktai G, et al. Primary ciliary dyskinesia: a consensus statement on diagnostic and treatment approaches in children. Eur Respir J. 2009 Dec;34(6):1264-76.

99 Knowles MR, Daniels LA, Davis SD, Zariwala MA, Leigh MW. Primary ciliary dyskinesia. Recent advances in diagnostics, genetics, and characterization of clinical disease. Am J Respir Crit Care Med. 2013 Oct;188(8): 913-22.

100 Lucas JS, Burgess A, Mitchison HM, Moya E, Williamson M, Hogg C; National PCD Service, UK. Diagnosis and management of primary ciliary dyskinesia. Arch Dis Child. 2014 Sep;99(9):850-6.

101 Gilbert CR, Chen A, Akulian JA, Lee HJ, Wahidi M, Argento AC, et al. The use of convex probe endobronchial ultrasoundguided transbronchial needle aspiration in a pediatric population: a multicenter study. Pediatr Pulmonol. 2014 Aug;49(8):807-15.

102 Dhooria S, Madan K, Pattabhiraman V, Sehgal IS, Mehta R, Vishwanath G, et al. A multicenter study on the utility and safety of EBUS-TBNA and EUS-B-FNA in children. Pediatr Pulmonol. 2016 Oct;51(10):1031-9. 
103 Nicolai T, Fischer-Truestedt C, Reiter K, Grantzow R. Subglottic hemangioma: a comparison of CO2 laser, Neodym-Yag laser, and tracheostomy. Pediatr Pulmonol. 2005 Mar;39(3):233-7.

104 Lee KS, Chen BN, Yang CC, Chen YC. CO2 laser supraglottoplasty for severe laryngomalacia: a study of symptomatic improvement. Int J Pediatr Otorhinolaryngol. 2007 Jun;71(6):889-95.

105 Lim J, Hellier W, Harcourt J, Leighton S, Albert D. Subglottic cysts: the Great Ormond Street experience. Int J Pediatr Otorhinolaryngol. 2003 May;67(5):461-5.

106 Welkoborsky HJ, Hinni ML, Moebius H, Bauer L, Ostertag H. Microscopic examination of iatrogenic subglottic tracheal stenosis: observations that may elucidate its histopathologic origin. Ann Otol Rhinol Laryngol. 2014 Jan;123(1):25-31.
107 Nouraei SA, Singh A, Patel A, Ferguson C, Howard DJ, Sandhu GS. Early endoscopic treatment of acute inflammatory airway lesions improves the outcome of postintubation airway stenosis. Laryngoscope. 2006 Aug;116(8):1417-21.

108 De Gracia J, Culebras M, Alvarez A, Catalán E, De la Rosa D, Maestre J, et al. Bronchoscopic balloon dilatation in the management of bronchial stenosis following lung transplantation. Respir Med. 2007 Jan;101(1):2733.

109 Lund ME, Force S. Airway stenting for patients with benign airway disease and the Food and Drug Administration advisory: a call for restraint. Chest. 2007 Oct;132(4): 1107-8.

110 Nicolai T. Airway stents in children. Pediatr Pulmonol. 2008 Apr;43(4):330-44.

111 Serio P, Fainardi V, Leone R, Baggi R, Grisotto L, Biggeri A, et al. Tracheobronchial obstruction: follow-up study of 100 children treated with airway stenting. Eur J Cardiothorac Surg. 2014 Apr;45(4):e100-9.
112 Antón-Pacheco JL, Luna C, García E, López $\mathrm{M}$, Morante $\mathrm{R}$, Tordable $\mathrm{C}$, et al. Initial experience with a new biodegradable airway stent in children: is this the stent we were waiting for? Pediatr Pulmonol. 2016 Jun 51(6):607-12.

113 Richter GT, Ryckman F, Brown RL, Rutter MJ. Endoscopic management of recurrent tracheoesophageal fistula. J Pediatr Surg. 2008 Jan;43(1):238-45

114 de Blic J, Marchac V, Scheinmann P. Complications of flexible bronchoscopy in children: prospective study of 1,328 procedures. Eur Respir J. 2002 Nov;20(5):1271-6.

115 Rosenthal M. Bronchoscopy and infection. Paediatr Respir Rev. 2003 Jun;4(2):143-6.

116 AWMF. German Association of the Scientific Medical Societies (AWMF) - Standing Guidelines Commission. 